\title{
Combination of Ficus Carica Leaves Extract and Ubiquinone in a Chronic Model of Lithium Induce Reproductive Toxicity in Rats: Hindrance of Oxidative Stress and Apoptotic Marker of Sperm Cell Degradation
}

\author{
${ }^{1}$ Shimaa A. Haredy, ${ }^{2}$ Tamer S. Imam and ${ }^{1}$ Omar A. Ahmed-Farid \\ ${ }^{1}$ Department of Physiology, National Organization for Drug Control and Research (NODCAR), Giza 12553, \\ Egypt. \\ ${ }^{2}$ Department of Forensic Medicine and Toxicology, Faculty of Veterinary Medicine, Zagazig University, \\ Zagazig 44111, Egypt.
}

\begin{abstract}
Lithium carbonate $(L C)$ is the most widely used as antipsychotic drug and can suppress reproductive performance via testicular toxicity and induction of oxidative stress. The aim of the study was to investigate biological activities of Ficus carica extract (FC) and ubiquinone (Coq10) against LC induced reproductive toxicity in male rats. For this purpose forty two Wistar albino rats were used in this study and allocated into seven groups 6 of each. $1^{\text {st }}$ groups was served as normal control rats, received distill water $(C) .2^{\text {nd }}$ groups orally treated with $200 \mathrm{mg} / \mathrm{kg}$ body weight of Ficus carica extract (FE). $3^{\text {rd }}$ groups orally administered with 20 $\mathrm{mg} / \mathrm{kg}$ body weight of CoQ10 (CoQ10). $4^{\text {th }}$ groups orally treated with $25 \mathrm{mg} / \mathrm{kg}$ body weight of Lithium carbonate $(L C) .5^{\text {th }}$ group simultaneously treated with $25 \mathrm{mg} / \mathrm{kg}$ body weight of Lithium carbonate and $200 \mathrm{mg} / \mathrm{kg}$ b.w of FE $(F C+L C)$. $.6^{\text {th }}$ group simultaneously treated with $25 \mathrm{mg} / \mathrm{kg}$ body weight of Lithium carbonate and CoQ10 (20 mg/kg b.w) (LC+CoQ10). $7^{\text {th }}$ groups treated with $25 \mathrm{mg} / \mathrm{kg}$ body weight of Lithium carbonate, FE (200mg/kg b.w) and CoQ10 $(20 \mathrm{mg} / \mathrm{kg} \mathrm{b.w})(F C+C o Q 10+L C)$. The experiment lasted for 60 days. Revealed data showed that the LC induces significant $(P<0.05)$ increase in serum ALT, AST level, testicular GSSG, NO, MDA and 8-hydroxy-2-deoxyguanosine $(80 H d G)$. But showed significant $(P<0.05)$ decrease in testicular GSH, endogenous antioxidant enzymes (SOD and CAT), cell energy (ATP), testosterone level and semen quality [Sperm cell concentration (SCC), mass motility (MM) and individual motility \% (IM)]. On the other hand, FC, CoQ10 and their combination ameliorate negative impacts exhibited by LC. Data was confirmed by histological examination and Immunohistochemical staining for caspase-3 (as proapoptotic marker) of testes which revealed pathological alteration in LC, significant recovery in $F C$, CoQ10 and $F C+C o Q 10+L C$. In conclusion, the present study suggests that $F C, C o Q 10$ and their combination ameliorate $L C$-induced reduction in reproductive performance in male rats.
\end{abstract}

Keywords: Ficus carica, CoQ10, Lithium, semen quality, Caspase-3 and rats.

\section{Introduction}

The use of antipsychotic drugs carries a depletion balance between the avail of relieving psychotic symptoms and the hazard from some of troubling adverse effect. Sexual disruption is common among the patients taking antipsychotic drugs, but this area has been relatively neglected up to date (Finn $\boldsymbol{e t}$ al., 1990). Infertility is one of the essential health problems for human or animal production. Lithium is a psychiatry drug, being used in the treatment and prophylaxis of bipolar affective disorder, but also in antidepressant-resistant patients Lithium has been applied as a first drug for mood stabilizer (Hollister and Csernansky, 1990). Common adverse effects may include GI distress, dizziness, fatigue, sedation, ataxia, convulsions, decrease thyroid function, intestine, liver, brain, reproductive and endocrine systems and other organs (Ullah and Khan, 2014). Plants and derivatives of plant played an important role in world health and have long been known to possess biological activity. Thirty percent of all recent drugs are derived from plants. For several hundred years, people around the world have used locally grown plants as supplements to energize, vitalize, and eventually to improve male sexual functions (Ahmed-Farid et al., 2014). Ficus carica leaves are one of the oldest plants has been traditionally used for metabolic, cardiovascular, respiratory, antispasmodic, anti-inflammatory and reproductive disorders (Vikas et al., 2010). It has high vitamins, minerals, and phenolic contents which play a very important role in its antioxidant capacity (Veberic et al., 2008). Ubiquinone (CoQ10) also is known as a coenzyme10 that is ubiquitous in the bodies of most animals. This fat soluble substance, which resembles a vitamin, is present in most eukaryotic cells, primarily in the mitochondria (Mancini et al., 1998). It is a component of the electron transport chain and participates in aerobic cellular respiration, which generates energy in the form of ATP. CoQ10 is an antioxidant molecule, component of the respiratory chain. Recently numerous studies have been performed to investigate the Coq10 supplementation for infertile male as 
antioxidants to improve seminal parameters (Safarinejad et al., 2012). In sperm cells, CoQ10 is concentrated in the mitochondrial, where it is involved in energy production. It also functions as an antioxidant, preventing lipid peroxidation of sperm membranes. Recent studies showed that CoQ10 improving semen quality in male with idiopathic infertility (Lewin and Lavon, 1997). The aim of the study was to investigate biological activities of Ficus carica extract (FC) and ubiquinone (Coq10) against LC induces hepatic and reproductive toxicity in male rats.

\section{1-Experimental animals:}

\section{Materials and methods}

Wistar albino male rats (180-200 g) obtained from the National organization for drug control and research (NODCAR) animal house, NODACR, Giza, Egypt, was used for the study. The rats were housed in wire mesh cages under standard conditions (temperature $25-28^{\circ} \mathrm{C}, 12 \mathrm{~h}$ light and $12 \mathrm{~h}$ darkness cycles). Animals were fed with pelleted standard rat diet and water ad libitum. Generally, the study was conducted in accordance with the recommendations from the declaration of Helsinki on guiding principles in care and use of animals.

\section{2-Extract preparation:}

Approximately $2000 \mathrm{~g}$ of Ficus carica leaves was placed in a clean, flat-bottomed glass container and soaked in ten volume of ethanol $70 \%$. The container with its contents was sealed and kept for 3 days. Then extraction was carried out using ultrasonic sound bath accompanied by sonication (40 minutes). The content filtrated by a piece of clean, white cotton material. The extract then was filtered through Whatman filter paper (Bibby RE200, Sterilin Ltd., UK) and dried by electric oven at $45^{\circ} \mathrm{C}$ temperature and continued up to obtain ethanol (205 g) extract. The gummy extract was stored in an air tight container.

\section{3-Experimental design}

Forty two (42) rats were assigned into 7 groups of six animals each. $1^{\text {st }}$ groups was normal control rats, received distill water (C). $2^{\text {nd }}$ groups treated with Ficus carica extract $200 \mathrm{mg} / \mathrm{kg}$ body weight (FE). $3^{\text {rd }}$ groups treated with $20 \mathrm{mg} / \mathrm{kg}$ body weight of CoQ10 (CoQ10). $4^{\text {th }}$ groups orally treated with $25 \mathrm{mg} / \mathrm{kg}$ body weight of Lithium carbonate (LC). $5^{\text {th }}$ groups treated with $25 \mathrm{mg} / \mathrm{kg}$ body weight of Lithium carbonate and FE $(200 \mathrm{mg} / \mathrm{kg}$ b.w) $(\mathrm{LC}+\mathrm{FE}) .6^{\text {th }}$ groups treated with $25 \mathrm{mg} / \mathrm{kg}$ body weight of Lithium carbonate and CoQ10 (20 mg/kg b.w) (LC+ CoQ10). $7^{\text {th }}$ groups treated with $25 \mathrm{mg} / \mathrm{kg}$ body weight of Lithium carbonate, FE (200mg/kg b.w) and CoQ10 (20 mg/kg b.w) (LC + FE +CoQ10). All the administrations were given via oral intubation and the experiment maintained for 60 days.

\section{4-Blood and tissues collection}

Animals were scarified after 60 days of treatments, blood samples were collected from the retro-orbital plexus. Blood was collected and allows clotting to separate serum. Serum was separated with non-coagulant by centrifugation at 3000 r.p.m. for 20 minutes and kept at $-20{ }^{\circ} \mathrm{C}$ until further biochemical analysis (ALT, AST and testosterone).

\section{5-Tissues collection}

Testes samples were taken at the time of sacrifice from 6 rats from each group. The testes were immediately excised, preserved in $10 \%$ neutral buffered formalin until processing for histopathological examination and another testis was homogenized using a homogenizer surrounded with an ice jacket and with $10 \%$ potassium chloride in a dilution 1:10 of tissue homogenate, followed by centrifugation in cooling centrifuge at $4^{\circ} \mathrm{C}$ for $20 \mathrm{~min}$. at 5000 r.p.m. The homogenates were used for the determination of GSH, GSSG, NO, MDA, 8-hydroxy-2-deoxyguanosine (8OHdG), superoxidedismutase (SOD), catalase (CAT) and ATP,

\section{6-Biochemical parameters}

Determination of Serum activities of AST and ALT was estimated according to Reitman and Frankel 1957.

\section{7-Determination of tissue GSH ( $\mu \mathrm{mol} / \mathrm{g}$ tissue) and GSSG ( $\mu \mathrm{mol} / \mathrm{g}$ tissue) levels by HPLC:}

The thiols compounds of oxidized and reduced glutathione were detected by HPLC system of Agilent HP 1200 series (USA) that consisted of quaternary pump, a column oven, Rheodine injector and $20 \mu 1$ loop, UV variable wavelength detector. The report and chromatogram taken from Chemstation program purchased from Agilent. $30 \mathrm{~cm} \times 3.9 \mathrm{~mm} \mathrm{C}-18 \mu$ Bondapak column was used. The flow rate was $1 \mathrm{ml} / \mathrm{min}$ and UV detection at wavelength $190 \mathrm{~nm}$ was applied. $0.0025 \mathrm{M}$ sodium phosphate buffer, $\mathrm{pH} 3.5$, containing $0.005 \mathrm{M}$ tetrabutylammonium phosphate and $13 \%$ methanol was used as mobile phase. Samples were compared to glutathione (oxidized and reduced) reference standard purchased from Sigma Chemical Co. The results were expressed as $\mu \mathrm{mol} / \mathrm{g}$ tissue (Jayatilleke and Shaw, 1993). 


\section{8-Determination of tissue NO ( $\mu \mathrm{mol} / \mathrm{g}$ tissue) by HPLC:}

Nitric oxide level was determined using Agilent HP 1200 series HPLC apparatus (USA) as described above. The analytical column was anion exchange PRP-X100 Hamilton, 150 x $4.1 \mathrm{~mm}, 10 \mu \mathrm{m}$. The mobile phase was a mixture of $0.1 \mathrm{M} \mathrm{NaCl}$ - methanol, at a volume ratio 45:55.The flow rate of $2 \mathrm{ml} / \mathrm{min}$, wavelength adjusted to $230 \mathrm{~nm}$. The resulting chromatogram identified the concentration from the sample as compared to that of the standard purchased from Sigma Aldrich (Papadoyannis et al., 1999).

\section{9-Determination of tissue MDA (nmol/g tissue) by HPLC:}

For determination of MDA levels; the samples were analyzed on an Agilent HP 1200 series HPLC apparatus (USA) as described above. The analytical column was Supelcosil C18 $\left(5 \mu \mathrm{m}\right.$ particle and $80 \mathrm{~A}^{\circ}$ pore size) $(250 \times 4.6$ ID). The mobile phase was $82.5: 17.5(\mathrm{v} / \mathrm{v}) 30 \mathrm{mM}$ monobasic potassium phosphate $(\mathrm{pH} 3.6)$ methanol and the flow rate was $1.2 \mathrm{ml} / \mathrm{min}$, wavelength $250 \mathrm{~nm}$ was applied for detection. MDA standard was prepared by dissolving $25 \mu \mathrm{l} 1,1,3,3$ tetraethoxypropane (TEP) in $100 \mathrm{ml}$ of water to give a $1 \mathrm{mM}$ stock solution. Working standard was prepared by hydrolysis of $1 \mathrm{ml}$ TEP stock solution in $50 \mathrm{ml} 1 \%$ sulfuric acid and incubation for $2 \mathrm{~h}$ at room temperature. The resulting MDA standard of $20 \mathrm{nmol} / \mathrm{ml}$ was further diluted with $1 \%$ sulfuric acid to yield the final concentration of $1.25 \mathrm{nmol} / \mathrm{ml}$ to get the standard for the estimation of total MDA (Karatepe, 2004).

\section{0-Determination of tissue 8-OHdG (pg/ g tissue) by HPLC:}

The separation of 8-OHdG was performed with an Agilent HP 1200 series HPLC apparatus (USA) as described above. The analytical column was Supelcosil C18 $\left(5 \mu \mathrm{m}\right.$ particle and $80 \mathrm{~A}^{\circ}$ pore size $)(250 \mathrm{x} 4.6 \mathrm{ID})$.

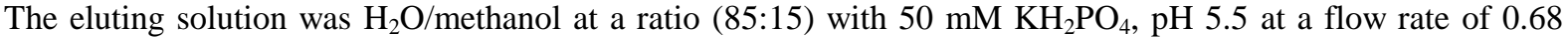
$\mathrm{ml} / \mathrm{min}$. the UV detector was set at $254 \mathrm{~nm}$. The resulting chromatogram identified the concentration from the sample as compared to that of the standard purchased from Sigma Aldrich (Lodovici et al., 1997).

\section{1-Determination of tissue CAT (U/mg protein) by spectrophotometer:}

Catalase activity was measured by spectrophotometric method based on the decomposition of $\mathrm{H}_{2} \mathrm{O}_{2}$ (Aebi, 1984).

\section{2-Determination of tissue SOD (U/mg protein) by spectrophotometer:}

SOD activity was assayed in the liver tissue by the method of (Marklund and Marklund, 1974) at $420 \mathrm{~nm}$ for $1 \mathrm{~min}$ on a UV-Vis Shimadzu spectrophotometer (2450). Activity was expressed as the amount of enzyme that inhibits the autooxidation of pyrogallol by $50 \%$, which is equal to $1 \mathrm{U} / \mathrm{mg}$ protein.

\section{3-Determination of tissue ATP ( $\mu \mathrm{mol} / \mathrm{g}$ tissue) by HPLC:}

Determination of tissue ATP was performed by HPLC according to Teerlink et al. (1993) with some modifications. The separation of tissue ATP was performed with an Agilent HP 1200 series HPLC apparatus (USA) as described above. The analytical column was Ultrasphere ODS EC 250 x $4.6 \mathrm{~mm}$ column. Mobile phase A consisted of $0.06 \mathrm{~mol} / 1 \mathrm{~K}_{2} \mathrm{HPO}_{4}$ and $0.04 \mathrm{~mol} / 1 \mathrm{KH}_{2} \mathrm{PO}_{4}$ dissolved in deionized water and adjusted to pH 7.0 with $0.1 \mathrm{~mol} / \mathrm{K} \mathrm{KOH}$, while mobile phase B consisted of $100 \%$ acetonitrile. Flow rate of the mobile phase was $1.2 \mathrm{ml} / \mathrm{min}$. ATP in the samples were identified by comparison with standards purchased from Sigma Aldrich. The report and chromatograms were taken from chemstation program at wave length $254 \mathrm{~nm}$.

\section{4-Determination of serum testosterone level}

The serum was stored at $-20{ }^{\circ} \mathrm{C}$ and assay was completed within three months. For determination of serum testosterone by ELISA (Enzyme Linked Immunosorbant Assay), the kit was obtained from Fortrees Diagnostic Limited, United Kingdom and north Ireland according to the methods of Saxema et al., 1968.

Semen analysis

\section{Sample preparation:}

The testes and caudal epididymis were gently excised and testes were weighted and homogenized in saline $(10 \%$ w/v) Samples were centrifuged at $(4500 \mathrm{rpm})$ for 15 minutes, the supernatant was isolated and stored at $-20^{\circ} \mathrm{C}$ until assay. Caudal epididymis was minced by using sharp scissors to release sperm in $1 \mathrm{ml}$ of PBS $(\mathrm{pH}=7.4)$.

Mass motility:

A drop of freshly collected semen was placed on a slide kept near body temperature $\left(37-38{ }^{\circ} \mathrm{C}\right)$ and was examined under low magnification (X100), motility of semen samples were rated according to the vigor of the motility of sperms (El-Sherbiny, 1987) as follows:

1. Seminal samples showing very vigorous movement were rated 5. 2. Seminal samples showing vigorous movement were rated 4. 3. Seminal samples showing moderate movement were rated 3. 4. Seminal samples showing slow movement were rated 2. 
5. Seminal samples showing very slow movement were rated 1.6. Seminal samples showing no movement were rated 0 .

\section{Percentage of individual progressive motility of spermatozoa:}

Immediately after each collection, it was assessed by microscopic examination by placing a small drop of fresh semen on a clean warm glass slide $\left(37^{\circ} \mathrm{C}\right)$, diluted with two drops of warm $0.9 \% \mathrm{NaCl}$ and covered with a cover slip. Examination is made under the high power (X400) according to El-Sherbiny (1987).

Sperm cell concentration:

$500 \mu \mathrm{L}$ of the sperm suspension was diluted with formaldehyde fixative (10\% formalin in PBS). Approximately $10 \mu \mathrm{L}$ from the diluted solution was transferred into a haemocytometer and let to stand for $7 \mathrm{~min}$. Then the settled sperms were counted and evaluated per 250 small squares of a haemocytometer (Seed et al., 1996).

\section{Immunohistochemical staining of caspase-3}

The paraffinic testis were cut into $5 \mu \mathrm{m}$ sections and Launched on positively charged slides for caspase$3 \mathrm{IHC}$. Sections were dewaxed, rehydrated and autoclaved at $120^{\circ} \mathrm{C}$ for $10 \mathrm{~min}$ in $10 \mathrm{Mm}$ citrate buffer (pH 6). Wash uses PBS ( $\mathrm{pH}$ 7.2), and then add $0.3 \% \mathrm{H}_{2} \mathrm{O}_{2}$ in methanol for $15 \mathrm{~min}$ for blocking endogenous peroxidase. Slides washed again in PBS and blocking was completed by adding blocking buffer. Incubate for $30 \mathrm{~min}$ at room temperature. Caspase-3 Polyclonal Antibody (Cat. No. PA1-29157, Thermo Fisher Scientific Co., USA), was added after dilution by PBS (1:1000) and incubated for $30 \mathrm{~min}$. The slides were washed three times with wash buffer each for 3 min secondary antibody (Cat. No. 61-9520, Thermo Scientific Co., USA) was applied to tissue sections and incubated for $30 \mathrm{~min}$. The slides were washed three times for 3 min with wash buffer. Metal Enhanced DAB Substrate Working Solution was added to the tissue and incubated 10 min wash two times for 3 min each with wash buffer. Adequate amount of hematoxylin stain was added to the slide to cover the entire tissue surface for counterstaining (Bancroft and Cook, 1994).

\section{Histopathological examination:}

Samples were taken from the testis of rats in different groups and fixed in 10\% neutral buffered formalin for twenty four hours. Washing was done in tap water then serial dilutions of alcohol (methyl, ethyl and absolute ethyl) were used for dehydration. Specimens were cleared in xylene and embedded in paraffin at 56 degree in hot air oven for twenty four hours. Paraffin bees wax tissue blocks were prepared for sectioning at 4 microns by slidge microtome. The obtained tissue sections were collected on glass slides, deparaffinized and stained by hematoxylin and eosin stains (Banchroft $\boldsymbol{e t}$ al; 1996) for histopathological examination through the electric light microscope.

\section{Statistical analysis}

The values were expressed as the mean \pm SE for the 6 rats in each group. Differences between groups were assessed by one way analysis of variance (ANOVA) using SAS. Statistical analysis of the obtained data was performed using the general linear model (GLM). Significant differences among means were evaluated using Duncan's Multiple Range Test.

The following linear model was applied:

$\mathrm{Yij}=\mu+\alpha \mathrm{i}+\xi \mathrm{ij}$

Yij = Observation measured

$\mathrm{M}=$ Overallmean

$\alpha \mathrm{i}=$ Effect of treatment .

$\xi \mathrm{ij}=$ Experimental error assumed to be randomly distributed $(\sigma 2=0)$.

\section{Results}

Table 1: Prophylactic effects of FC, Coq10 and their combination on liver function (ALT and AST) in serum of rats treated with LC.

\begin{tabular}{|l|c|c|}
\hline \multicolumn{1}{|c|}{ Groups } & \multicolumn{2}{c|}{ Parameters } \\
\cline { 2 - 3 } & ALT & $\begin{array}{c}\text { AST } \\
\text { U/L }\end{array}$ \\
\hline Control & $26.56 \pm 1.84$ & $37.56 \pm 0.9$ \\
\hline FE & $30.05 \pm 1.11$ & $39.63 \pm 1.19$ \\
\hline CoQ10 & $27.22 \pm 0.99$ & $41.54 \pm 0.72$ \\
\hline L & $42.03 \pm 2.72 \mathrm{a}$ & $59.93 \pm 1.65 \mathrm{a}$ \\
\hline FE + L & $25.64 \pm 1.57 \mathrm{~b}$ & $39.58 \pm 1.45 \mathrm{~b}$ \\
\hline CoQ10 + L + CoQ10 + L & $34.73 \pm 2.25 \mathrm{ab}$ & $49.53 \pm 1.36 \mathrm{ab}$ \\
\hline
\end{tabular}

Data are expressed as Mean \pm S.E.M for 6 rats /group.

a significant difference from control group at the same column with one way ANOVA at $\mathrm{P}<0.05$.

$\mathrm{b}$ significant difference from $\mathrm{L}$ at the same column with one way ANOVA at $\mathrm{P}<0.05$. 
As showed in Table 1, records the Prophylactic effects of FC, Coq10 and their combination on liver function (ALT and AST) in serum of rats treated with LC. Lithium caused significant $(\mathrm{P}<0.05)$ elevation of serum ALT and AST. FC, Coq10 and their combination showed amelioration effect for liver function by decreasing ALT and AST in serum level.

Table 2: Prophylactic effects of FC, Coq10 and their combination on oxidative stress markers (GSH, GSSG and NO) in testes of rats treated with LC

\begin{tabular}{|c|c|c|c|}
\hline \multirow{2}{*}{ Groups } & \multicolumn{3}{|c|}{ Parameters } \\
\hline & $\begin{array}{c}\text { GSH } \\
\mu \mathrm{mol} / \mathrm{g} \text { tissue }\end{array}$ & $\begin{array}{c}\text { GSSG } \\
\mu \mathrm{mol} / \mathrm{g} \text { tissue }\end{array}$ & $\begin{array}{c}\text { NO } \\
\mu \mathrm{mol} / \mathrm{g} \text { tissue }\end{array}$ \\
\hline Control & $13.93 \pm 0.59$ & $0.91 \pm 0.05$ & $0.56 \pm 0.05$ \\
\hline CoQ10 & $18.13 \pm 0.92$ & $0.99 \pm 0.1$ & $0.49 \pm 0.02$ \\
\hline $\mathbf{L}$ & $9.71 \pm 0.49 \mathrm{a}$ & $1.85 \pm 0.09 \mathrm{a}$ & $0.98 \pm 0.07 a$ \\
\hline $\mathbf{F E}+\mathbf{L}$ & $12.63 \pm 0.84 b$ & $1.33 \pm 0.07 b$ & $0.73 \pm 0.03 b$ \\
\hline $\mathrm{FE}+\mathrm{CoQ} 10+\mathrm{L}$ & $14.23 \pm 0.83 b$ & $1.07 \pm 0.09 \mathrm{~b}$ & $0.58 \pm 0.03 b$ \\
\hline
\end{tabular}

Data are expressed as Mean \pm S.E.M for 6 rats /group.

a significant difference from control group at the same column with one way ANOVA at $\mathrm{P}<0.05$.

$\mathrm{b}$ significant difference from $\mathrm{L}$ at the same column with one way ANOVA at $\mathrm{P}<0.05$.

As showed in Table 2, records the Prophylactic effects of FC, Coq10 and their combination on oxidative stress markers (GSH, GSSG and NO) in testes of rats treated with LC. Lithium caused significant $(\mathrm{P}<0.05)$ elevation of GSSG, NO and decrease the level of GSH. On the other hand FC, Coq10 and their combination showed amelioration effect for oxidative stress markers (GSH, GSSG and NO) by decreasing GSSG, NO and increasing GSH in comparing with LC group.

Table 3: Prophylactic effects of FC, Coq10 and their combination on cell degeneration markers (MDA and $8 \mathrm{OHdG}$ ) in testes of rats treated with $\mathrm{LC}$

\begin{tabular}{|l|c|c|}
\hline \multicolumn{1}{|c|}{ Groups } & \multicolumn{2}{|c|}{ Parameters } \\
\cline { 2 - 3 } & $\begin{array}{c}\text { MDA } \\
\text { nmol/g tissue }\end{array}$ & $\begin{array}{c}\text { 80HdG } \\
\text { pg/g tissue }\end{array}$ \\
\hline Control & $26.28 \pm 0.96$ & $159.84 \pm 5.35$ \\
\hline FE & $23.42 \pm 0.85$ & $155.41 \pm 6.34$ \\
\hline CoQ10 & $22.31 \pm 1.06$ & $157.47 \pm 5.31$ \\
\hline L & $42.43 \pm 2.42 \mathrm{a}$ & $245.02 \pm 6.88 \mathrm{a}$ \\
\hline FE + L & $25.37 \pm 0.88 \mathrm{~b}$ & $173.38 \pm 2.89 \mathrm{ab}$ \\
\hline CoQ10 + L & $35.07 \pm 2.01 \mathrm{ab}$ & $185.95 \pm 5.69 \mathrm{ab}$ \\
\hline FE + CoQ10 + L & $26.92 \pm 0.95 \mathrm{~b}$ & $168.43 \pm 3.09 \mathrm{ab}$ \\
\hline
\end{tabular}

Data are expressed as Mean \pm S.E.M for 6 rats /group.

a significant difference from control group at the same column with one way ANOVA at $\mathrm{P}<0.05$.

$\mathrm{b}$ significant difference from $\mathrm{L}$ at the same column with one way ANOVA at $\mathrm{P}<0.05$.

As showed in Table 3, records the Prophylactic effects of FC, Coq10 and their combination on cell degeneration markers (MDA and $8 \mathrm{OHdG}$ ) in testes of rats treated with LC. Lithium caused significant $(\mathrm{P}<0.05)$ elevation of MDA and $8 \mathrm{OHdG}$. On the other hand FC, Coq10 and their combination showed amelioration effect for cell degeneration markers by decreasing MDA and $8 \mathrm{OHdG}$ in comparing with LC group.

Table 4: Prophylactic effects of FC, Coq10 and their combination on endogenous antioxidant (CAT and SOD) and cell energy (ATP) in testes of rats treated with LC

\begin{tabular}{|l|c|c|c|}
\hline \multicolumn{1}{|c|}{ Groups } & \multicolumn{2}{c|}{ Parameters } \\
\cline { 2 - 4 } & $\begin{array}{c}\text { SOD } \\
\text { CAT/g tissue }\end{array}$ & $\begin{array}{c}\text { ATP } \\
\boldsymbol{\mu g} / \mathbf{g} \text { tissue }\end{array}$ \\
\hline Control & $28.32 \pm 0.53$ & $54.3 \pm 1.7$ & $31.88 \pm 1.08$ \\
\hline FE & $27.38 \pm 1.52$ & $49.36 \pm 2.17$ & $28.23 \pm 1.72$ \\
\hline CoQ10 & $33.89 \pm 1.03$ & $53.62 \pm 2.31$ & $33.25 \pm 1.29$ \\
\hline L & $17.67 \pm 0.49 \mathrm{a}$ & $33.4 \pm 1.02 \mathrm{a}$ & $19.47 \pm 0.73 \mathrm{a}$ \\
\hline FE + L & $20.12 \pm 1.03 \mathrm{~b}$ & $40.64 \pm 1.17 \mathrm{~b}$ & $24.32 \pm 0.89 \mathrm{~b}$ \\
\hline CoQ10 + L & $24.82 \pm 0.61 \mathrm{~b}$ & $44.23 \pm 1.23 \mathrm{~b}$ & $28.04 \pm 0.91 \mathrm{~b}$ \\
\hline FE + CoQ10 + L & $26.22 \pm 0.81 \mathrm{~b}$ & $26.65 \pm 1.49 \mathrm{~b}$ & $26.72 \pm 0.74 \mathrm{~b}$ \\
\hline
\end{tabular}

Data are expressed as Mean \pm S.E.M for 6 rats /group.

a significant difference from control group at the same column with one way ANOVA at $\mathrm{P}<0.05$.

$\mathrm{b}$ significant difference from $\mathrm{L}$ at the same column with one way ANOVA at $\mathrm{P}<0.05$. 
As showed in Table 4, records the Prophylactic effects of FC, Coq10 and their combination on endogenous antioxidant (CAT and SOD) and cell energy (ATP) in testes of rats treated with LC. Lithium caused significant $(\mathrm{P}<0.05)$ reduction of endogenous antioxidant (CAT and SOD) and cell energy (ATP). On the other hand FC, Coq10 and their combination showed amelioration effect for CAT, SOD and ATP by increasing their levels in comparing with LC group.

Table 5: Prophylactic effects of FC, Coq10 and their combination on serum testosterone level and semen quality (SCC, MM and IM) of rats treated with LC.

\begin{tabular}{|l|c|c|c|c|}
\hline \multirow{2}{*}{ Groups } & \multicolumn{4}{c|}{ Parameters } \\
\cline { 2 - 6 } & Testosterone ng/ml & Sperm count x 10 $/$ gm cauda & MM grade & \% IM \\
\hline Control & $3.71 \pm 0.08$ & $129.24 \pm 6.39$ & $3.34 \pm 0.29$ & $79.15 \pm 2.36$ \\
\hline FE & $3.84 \pm 0.13$ & $134.83 \pm 6.64$ & $3.71 \pm 0.25$ & $81.62 \pm 1.03$ \\
\hline CoQ10 & $3.95 \pm 0.11$ & $144.31 \pm 4.21$ & $3.86 \pm 0.23$ & $84.66 \pm 1.42$ \\
\hline L & $2.16 \pm 0.07 \mathrm{a}$ & $71.47 \pm 4.6 \mathrm{a}$ & $2.18 \pm 0.21 \mathrm{a}$ & $49.59 \pm 1.98 \mathrm{a}$ \\
\hline FE + L & $3.31 \pm 0.07 \mathrm{~b}$ & $91.55 \pm 4.67 \mathrm{~b}$ & $2.71 \pm 0.15 \mathrm{~b}$ & $70.68 \pm 1.81 \mathrm{~b}$ \\
\hline CoQ10 + L & $2.91 \pm 0.08 \mathrm{ab}$ & $102.93 \pm 5.68 \mathrm{~b}$ & $2.92 \pm 0.26 \mathrm{ab}$ & $73.23 \pm 2.45 \mathrm{ab}$ \\
\hline FE + CoQ10 + L & $3.37 \pm 0.11 \mathrm{~b}$ & $117.63 \pm 5.14 \mathrm{~b}$ & $3.22 \pm 0.16 \mathrm{~b}$ & $75.35 \pm 1.2 \mathrm{~b}$ \\
\hline
\end{tabular}

Data are expressed as Mean \pm S.E.M for 6 rats /group.

a significant difference from control group at the same column with one way ANOVA at $\mathrm{P}<0.05$.

$\mathrm{b}$ significant difference from $\mathrm{L}$ at the same column with one way ANOVA at $\mathrm{P}<0.05$.

As showed in Table 5, records the Prophylactic effects of FC, Coq10 and their combination on serum testosterone and semen quality of rats treated with LC. Lithium caused significant $(\mathrm{P}<0.05)$ reduction of serum testosterone and decrease semen quality (SCC, MM and \% IM). On the other hand FC, Coq10 and their combination showed amelioration effect for testosterone level and semen quality parameters in comparing with LC group.

Immunohistochemical findings:

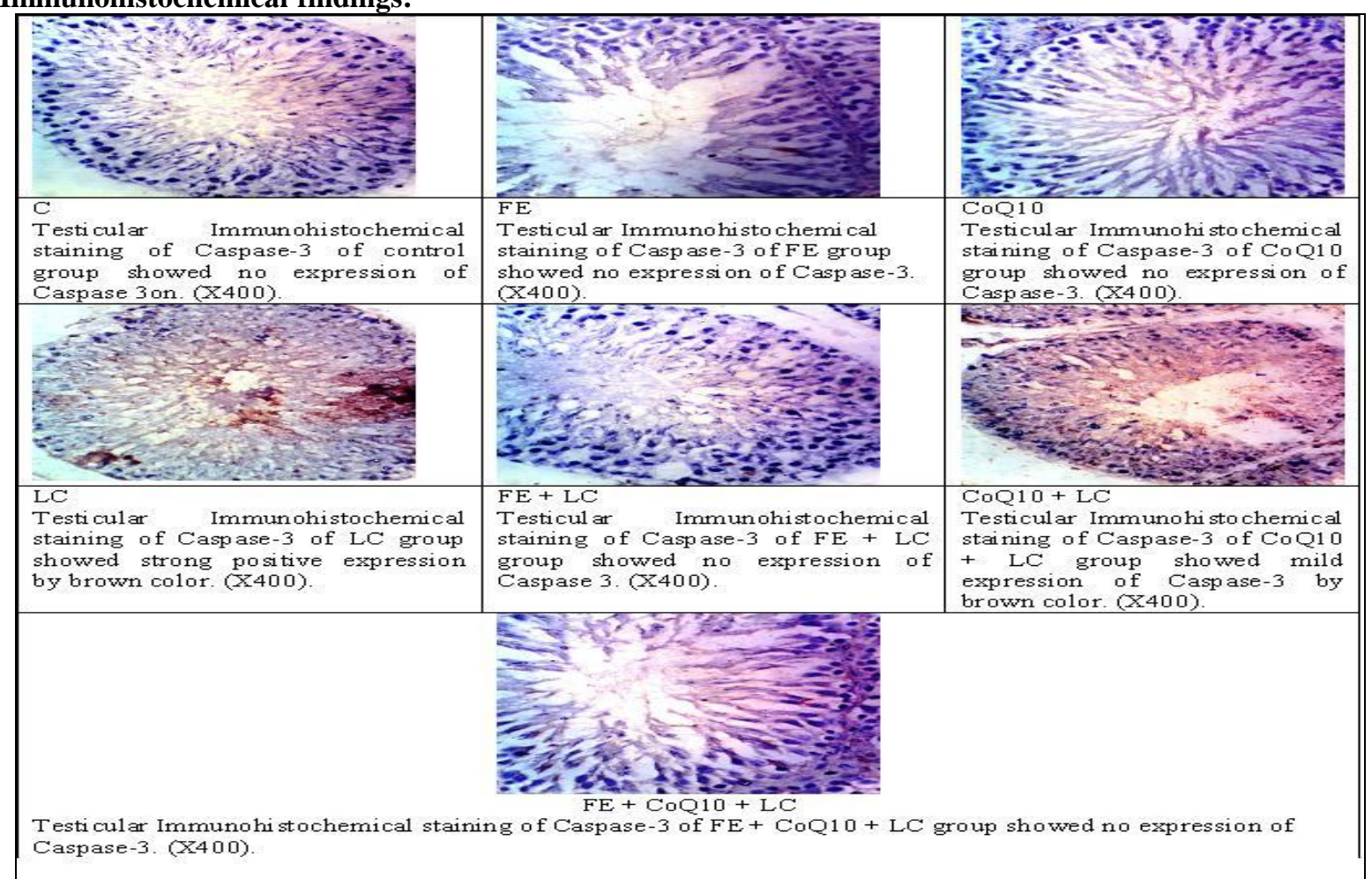

Fig. (1): Showing the immunoreactivity of caspase -3 counter stains with haematoxylin in testicular tissue of different groups. (X400). 
Histopathological findings:

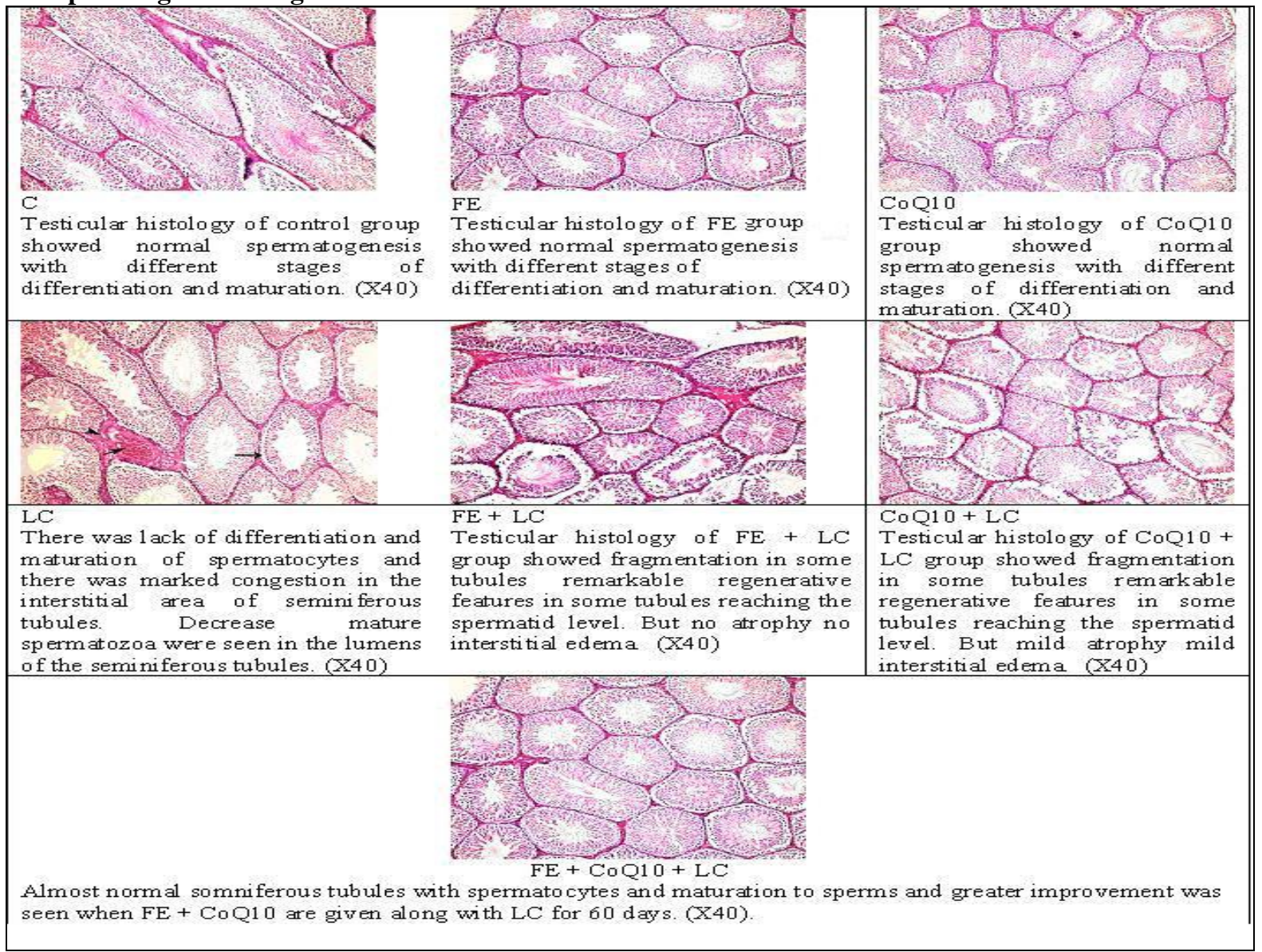

Fig. (2): Showing the histopathological results of rats testes protected by FC, CoQ10 or their combination against LC induction.

\section{Discussion}

Lithium, recently included into the essential elements, has been found to influence several metabolic processes and exert divergent effects both positive and negative (Kersten $\boldsymbol{e t}$ al., 1987). It is widely used in psychiatry as a mood stabilizer, treatment of depression and bipolar disorders. Chronic lithium intoxication is more common (Shastry, 2005). There is gradual accumulation due to decreased excretion. Obtained data showed significant increase due to lithium carbonate (LC) treatment on liver enzymes (ALT, AST), testes oxidative stress markers (MDA, GSSG, NO, 8OHdG) and decrease testes GSH, CAT, SOD and ATP in comparing with control group. Increase in liver enzymes and testes oxidative stress markers may be due to the accumulation of LC in liver tissue and decrease excretion by the kidney that may disrupt the cell function and increase cell damage (Tandon $\boldsymbol{e t}$ al., 1998). This finding was consisted with Vijaimohan et al. (2010) suggested that lithium intoxicated rats were accompanied by the elevation of TBARS production which is mainly based on lipid peroxidation (LPO) by indirect evidence by decreased antioxidant defense enzyme activities, suggesting oxidative stress in liver, testes tissue. 8-hydroxy-2-deoxyguanosine content is considered a sensitive biomarker of the oxidative DNA damage and repair (Kouda et al., 2001); there are several hundred reports linking increased concentrations of 8 -OHdG to increased against toxicity (Arnett et al., 2005). Obtained data describes the ability of LC to inhibit numerous antioxidant enzymes and disrupt mitochondrial ATP production in testes cells. The decrease in SOD and CAT activity occurs due to lipid peroxyl radicals and from an inactivation of their destruction products. Decrease of ATP production of LC treated group may be owed to lithium ion too large to pass through the proton exchange of ATP synthase complex and thus limit the flow of protons by blocking the proton pore, inhibiting ATP production (Rizak, 2014). In the present work, disrupted testosterone level and semen quality for LC treated animal compared to control group. These results are similar to Thakur et al. (2003) found that LC decrease testosterone level by promote Leydig cell degeneration that main cell responsible for testosterone production (primary gonadal failure). The number and size of Leydig cells were the best indication of the capacity of this cell to produce testosterone (Guo et al.., 2013). Decrease of semen quality may be attributed to the testosterone depletion. Testosterone was very important for the maintenance of quantitatively normal spermatogenesis in most mammalian species (Sharpe, 
1994). Histological examination of testes section showed lack of differentiation and maturation of spermatocytes, congestion in the interstitial area of somniferous tubules. These results are consisted with Mwaheb et al. (2016) finding that, Rats treated with $100 \mathrm{mg} / \mathrm{kg} / \mathrm{day}$ of LC showing irregular tubular wall and massive loss of spermatonic cells and massive necrosis of spermatocytes and spermatids.

Ficus carica leaves (FC) has been traditionally used in the treatment of different disorders such as gastrointestinal (indigestion, colic, loss of appetite and diarrhea), gout, ulcers and different disease (Tchombé and Louajri, 2015). They related this hepatoprotective activity to the presence of coumarins in the methanolic extract of their leaves. Obtained data showed the protective effect of FC against rats chronic administered with LC. Ficus carica leave extract showed significant decrease of liver enzymes (ALT and AST), testes oxidative stress markers (MDA, GSSG, NO and 8OHdG), increase endogenous antioxidant enzymes (CAT and SOD), testes cell energy (ATP), testosterone level and semen quality. The protective effect of FC by decreasing of liver enzymes and testes oxidative stress markers as protective agent for LC may be due to the phytochemical constituent (phenol, flavonoid, tannins and coumarins) that act as antioxidant by decreasing the production of reactive oxygen species (Perez-Garcia et al., 2000; Algohary et al., 2016). These finding are inagreement with Recknagel et al. (1989) they found hepatoprotective effect of FC against CCl4 intoxicated rats. Krishna et al. (2007) suggested that, the decrease in lipid peroxides may be due to the anti-oxidant effect of the extract by inhibition of cytochrome $\mathrm{P} 450$ s which impair the bioactivation of $\mathrm{CCl} 4$ into their corresponding reactive species. Endogenous antioxidant enzymes (CAT and SOD) and testes cell energy (ATP) were ameliorated by FC treatment in comparing with LC group that may be due to the role of flavanoids one of its active components, are known to be powerful antioxidant (Sule $\boldsymbol{e t} \boldsymbol{a l . , 2 0 1 2}$ ), as well as the flavanoids probability did so by reducing the accumulation of LC due to tannins which act as chelating agent (Mada $\boldsymbol{e t}$ al., 2014). The results of this study showed that the FC increase serum testosterone levels and semen quality (SCC, MM and IM) in comparing with LC group. The improvement of semen quality in FC group may be due to FC containing saponin that act as testosterone like action. These finding inagreement with Njoku-Oji et al. (2015) found Ficus carica increase semen quality and testosterone level in normal rats by positive effect on follicle stimulating hormone (FSH), promoting spermatogenesis and enhance testosterone level to be sufficient enough to maintain the maturation of the sperm cells that activated by a possible elevation of FSH. On a survey performed on rats, Samsulrizal et al. (2011) reported that Ficus has significant beneficial effects on the testosterone level, and sperm count in diabetic rats. In this study, testes histological examinations of the FC + LC group revealed that administration of FC leaf extracts prevented from some damage effects of LC. These preventive effects can be related to the presence of several antioxidants in FC that had been stated previously.

Ubiquinone (CoQ10) is an endogenous synthesized lipid soluble benzo- quinone compound that is found in most living cells in the body act as a diffusible electron carrier in the mitochondrial respiratory chain (Forbes et al., 2008). CoQ10 showed significant decrease of serum ALT and AST as a prophylactic effect against lithium toxicity. The decrease of liver enzymes may be due to membrane stabilizing role of CoQ10 which leads to reduction of ALT and AST leakage from liver. This results inagreement with Ali et al. (2010) who suggested that L-Carnitine and Coenzyme Q10 protected rats against $\mathrm{CCl}_{4}$ induce liver injury.

Lipid peroxidation triggers the denaturation of cell membrane, causing increased cell permeability, enzyme inactivation, and structural damage led to DNA mutations, and cell death. CoQ10 sowed significant decrease in testes oxidative stress markers (MDA, GSSG, NO and 8OHdG) and increase GSH that may be due to CoQ10 antioxidant activity, it could be involved in the protection of cell membranes from oxidative insult. Coenzyme Q10 shows effectiveness in counteracting free radicals-induced tissue damage. Antiradical effects of CoQ10 may prevent the initiation and propagation of lipid peroxidation in cellular membranes (Bentinger $\boldsymbol{e t}$ al.., 2007). Our results are similar to Mohammad et al. (2015) who found that CoQ10 and fish oil synergistically alleviate Aluminum induced suppression of testicular Steroidogenesis and antioxidant defense.

Antioxidant enzymes such as CAT and SOD the first line of defense against reactive oxygen species, and a decrease in their activity contributes to the oxidant attack on cells. The activity of CAT and SOD were significantly increased after CoQ10 supplementation. Obtained data are consisted with Lee et al. (2011) who found that, CoQ10 supplementation reduces oxidative stress and increase up regulation of antioxidant enzyme activity in patients with coronary artery disease. Increase ATP production for CoQ10 may be due to the role of CoQ10 in mitochondrial respiratory chain (MRC) to synthesize ATP via oxidative phosphorylation. MRC is consists of 5 enzyme complex I-V. CoQ10 is the predominant form of ubiquinone and serves as an electron carrier in MRC (Rahman and Hanna, 2009).

CoQ10 functions in biological fluids that are transfer electron in the mitochondrial respiratory chain and neutralization of $\mathrm{O}_{2}$ reactive species. CoQ10 in combination with LC showed ameliorating effect and improve testosterone level and semen quality after 60 days in comparing with LC group. The protection of CoQ10 against LC steroidogenesis (Testosterone) depletion this could be attributed to its capacity to restore testicular Zn content (Sadik, 2008). Likewise, testosterone is positively correlated with total antioxidant capacity (Demirbag et al., 2005). CoQ10 ameliorated testicular histopathological damage and increased the 
levels of testosterone and LH hormones of rabbits intoxicated with cadmium (Abdel-Hady and AbdelRahman, 2011).

The increase in sperm and motility may be due to neutralize ROS reaction. ROS considered the main source of loss sperm motility, decreased the capacity of sperm oocytes penetration and increase ATP depletion that affect on sperm axoneme and then inhibit mitochondrial functions, synthesis of DNA, RNA, and proteins (Ducci et al., 2002). Obtained data is in the same line of Abdul-Rasheed et al. (2010) whose found that the CoQ10 increased semen quality by decreasing oxidative stress markers in seminal plasma of Iraqi patients with male infertility.

Obtained data showed decrease ROS production in CoQ10 in combination with LC group that may prevent depolarization of mitochondrial membrane, and inhibit activation of caspase-3, and then decrease testis apoptosis. These results are inagreement with Gollapudi and Gupta (2016) who found that reversal of oxidative stress-induced apoptosis in T and B lymphocytes by CoQ10.

Combination between FC and CoQ10 as a protective effect against LC in liver, testes and semen quality may be due to the antioxidant, antiradical, chelating agent and cell membrane protective for these combination and ameliorate the harmful effects of LC and restoring liver function, oxidative stress markers, endogenous antioxidant enzymes, cell energy, semen quality, Caspase-3 and testes tissue almost normal in comparing with control group.

\section{Conclusion}

The results of the present study indicate that administration of CoQ10 or FC or their combination attenuates lithium induced liver and testes toxicity in rats through the decrease liver enzymes, testes oxidative stress markers, counteraction of free radicals, increasing cell energy and semen quality by its antioxidant property, antiapoptotic effect by decreasing DNA fragmentation, attenuation testes histopathological alteration and activation/overexpression of caspase-3. This leads to a considerable a natural remedy as protective agents for the management of reproductive toxicity.

\section{References}

[1]. Abdel-Hady, E-S. K. and Abdel-Rahman, G. H. (2011). Protective effect of coenzyme q10 on cadmium-induced testicular damage in male rabbits,American-Eurasian Journal of Toxicological Sciences 3; 153-160.

[2]. Abdul-Rasheed, O. F. Farid, Y.Y. and Al-Nasiri, U. S. (2010). Coenzyme Q10 and oxidative stress markers in seminal plasma of Iraqi patients with male infertility. Saudi Med J. 31(5):501-6.

[3]. Aebi, H. (1984). Catalase in Vitro. Method Enzym 105: 121- 126

[4]. Ahmed-Farid O. A, El-Sayed AI, Iraqi MM, Saad AM, Radwan AA. (2014). Comparative evaluation of different herbal formula and L-Carnitine on reproductive performance of male Moshtohor rabbits. ${ }^{\text {nd }}$ International conference on biotechnology applications in agriculture (ICBAA), Benha University, Moshtohor and Hurghada. 8-12.

[5]. Algohary, A. M. Ahmad-Farid, O. A. Abd-Elrazek, A. M. and Al-Baradie, R. S. (2016). Neuroprotective effects of herbal cocktail on cerebrovascular dysfunction in rats with induced hyperhomocysteinaemia. Biomed Res Ther, 3(12): 1045-1061.

[6]. Ali, S. A. Faddah, L. Abdel-Baky, A. and Bayoumi, A. (2010). Protective Effect of L-Carnitine and Coenzyme Q10 on CCl4Induced Liver Injury in Rats. Sci Pharm. 78: 881-896.

[7]. Arnett, S. D. Osbourn, D. M. Moore, K. D. Vandaveer, S. S. and Lunte, C. E. (2005). Determination of 8-oxoguanine and 8hydroxy-2'-deoxyguanosine in the rat cerebral cortex using microdialysis sampling and capillary electrophoresis with electrochemical detection. J Chromatogr B Analyt Technol Biomed Life Sci, 827: 16-25.

[8]. Banchroft, J. D. Stevens, A. and Turner, D. R. (1996): Theory and Practice of Histological Techniques. 4th Ed. Churchill Livingstone, New York, London, San Francisco, Tokyo.

[9]. Bancroft, J. D., and Cook, H. C. (1994). Manual of Histological Techniques and Their Diagnostic Application. Retrieved from https : // books . google . com / books ?id = R 0prAAAAMAAJ \& pgis $=1$.

[10]. Bentinger, M. Brismar, K. and Dallner, G. (2007). The antioxidant role of coenzyme Q, Mitochondrion 7; S41-S50.

[11]. Demirbag, R. Yilmaz, R. and Erel, O. (2005). The association of total antioxidant capacity with sex hormones, Scand. Cardiovasc. J. 39; 172-176.

[12]. Ducci, M. Gazzano, A. Tedeschi, D. Sighieri, C. and Martelli, F. (2002). Coenzyme Q10 levels in pigeon (Columba livia) spermatozoa. Asian J Androl; 4: 73-76.

[13]. El-Sherbiny, A. M. (1987). Seasonal variation in seminal characteristics of rabbits. M.Sc. Thesis, Fac. Agric., Ain Shams Univ., Egypt.

[14]. Finn, S. E. Bailey, J. M, Schultz, R. T. and Faber, R. (1990). Subjective utility ratings of neuroleptics in treating schizophrenia. Psychol Med 20: 843-848

[15]. Forbes, J. M. Coughlan, M. T. and Cooper, M. E. (2008). Oxidative stress as a major culprit in kidney disease in diabetes. Diabetes, 57, 1446-1454.

[16]. Gollapudi, S. and Gupta, S. (2016). Reversal of oxidative stress-induced apoptosis in T and B lymphocytes by Coenzyme Q10 (CoQ10). Am J Clin Exp Immunol; 5(2):41-47.

[17]. Guo, J. Zhou, H. Su, Z. Chen, B. Wang, G. Claire, Q. F. Wang, C. Q. F. Xu, Y. and Ge, R. (2013). Comparison of cell types in the rat Leydig cell lineage after ethane dimethanesulfonate treatment. ociety for Reproduction and Fertility. Reproduction. 145. 371-380.

[18]. Hollister, L. E. and Csernansky, J. G. (1990). Clinical Pharmacology and Psychotherapeutic Drugs, Churchill-Livingstone Inc. New York 132-133.

[19]. Jayatilleke, E. and Shaw, S. (1993). A high performance liquid chromatographic assay for reduced and oxidized glutathione in biological samples. Anal. Biochem., 214(2): 452-457. 
[20]. Karatepe, M. (2004). Simulatenous determination of ascorbic acid and free malondialdehyde in human serum by HPLC-UV. Chromatographic Line., 12:362-365.

[21]. Kersten, L. Bartha, J. and Braunlich, H. (1987). Early lithium-induced nephrotoxicity and changes of renal hemodynamics in rats. Biomed Biochim Acta 46: 845-853.

[22]. Kouda, K. Nakamura, H. Fan, W. Horiuchi, K. and Takeuchi, H. (2001). The relationship of oxidative DNA damage marker 8 hydroxydeoxyguanosine and glycoxidative damage marker pentosidine. Clin Biochem, 34: 247-50.

[23]. Krishna Mohan, G. Pallavi, E. Ravi Kumar. B. Ramesh. M. and Venkatesh, S. (2007). Hepatoprotective activity of Ficus carica Linn. Leaf extract against carbon tetrachloride induced hepatotoxicity in rats, DARU, 15(3), pg: 162-166.

[24]. Lee, B. M. D. Huang, Y. Chen, S. and Lin, P. (2011). Coenzyme Q10 supplementation reduces oxidative stress and increase antioxidant enzyme activity in patients with coronary artery disease. Nutrition, Xxx; $1-6$.

[25]. Lewin, A. and Lavon, H. (1997). The effect of coenzyme Q-10 on sperm motility and function. Mol Aspects Med; 18 S213-S219.

[26]. Lodovici, M. Casalini, C. Briani, C. and Dolara, P. (1997). Oxidative liver DNA damage in rats treated with pesticide mixtures. Toxicology; 117: 55-60.

[27]. Mada, S. B. Inuwa, H. M. Abarshi, M. M. Mohammed, H. A. and Aliya, A. (2014): Hepatoprotectiveeffect of Momordica charantia extract against CCL4 induced liver damage in rats. British Journal ofPharmaceutic Research., 4(3): 368-380.

[28]. Mancini, A. Conte, G. Milardi, D. de Marinis, L. and Littarru, G. P. (1998). Relationship between sperm cell ubiquinone and seminal parameters in subjects with and without varicocele," Andrologia, 30, (1):1-4

[29]. Marklund, S. and Marklund, G. (1974): Involvement of the superoxide anion radical in the autoxidation of pyrogallol and a convenient assay for superoxide dismutase. Eur. J. Biochem., 47(3):469-474.

[30]. Mohammad, N. S. Arafa, M. H. and Atteia, H. H. (2015). Coenzyme Q10 and fish oil synergistically alleviate aluminum chloride-induced suppression of testicular steroidogenesis and antioxidant defense. Free Radical Research. 49(11):1319-34.

[31]. Mwaheb, M. A. Sayed, O. N. and Mohamed, S. H. (2016). Protective Effect of Rosemary (Rosmarinus officinalis) Extract on Lithium-Induced Renal and Testis Toxicity in Albino Rats. Journal of Drug Metabolism and Toxicology. 7:4. DOI: 10.4172/21577609.1000216

[32]. Njoku-Oji, N. N. Osaji, D. E. Ifegwu, N. O. Uchefuna, R. C. and Ezejindu, D. N. (2015). Effects of aqueous extract of Ficus carica leaf on some reproductive parameters in normal adult male wistar Rats. International Journal of Multidisciplinary Research and Development; 2 (2): 57 7-583.

[33]. Papadoyannis, L. N. Samanidou, V. F. and Nitsos, Ch. C. (1999). Simultaneous determination of nitrite and nitrate in drinking water and human serum by high performance anion-exchange chromatography and UV detection. J. Liq. Chrom. Rel. Technol., 22(13): $2023-2041$

[34]. Perez-Garcia, F. Adzet, T. and Canigueral, S. (2000). Activity of artichoke leaf extract on reactiveoxygen species in human leukocytes. FreeRadical Res; 33:661-665.

[35]. Rahman, S. and Hanna, M. G. (2009). Mitochondrial disease disorders: diagnosis and new treatment in mitochondrial diseases. J Neurol Neurosurg Psychiatry; 80: 943-953.

[36]. Recknagel, R. O. Glende, E. A. Dolak, J. A. and Waller, R. L. (1989). Mechanisms of carbon tetrachloride toxicity. Pharmacol Ther; 43:139-154.

[37]. Reitman, S. and Frankel, S. (1957). Calorimetric determination of AST and ALT activity Am J Clin Path 28: 56-63.

[38]. Rizak, J. D. (2014). The Inhibition of ATP Production by Lithium: A Preliminary Study in Whole Mitochondria from Rat Brain and a Putative Model for Bipolar Disorder. Annals of Psychiatry and Mental Health. 2(3): 1014.

[39]. Sadik, N. A. H. (2008). Effects of Diallyl Sulfide and Zinc on Testicular Steroidogenesis in Cadmium-Treated Male Rats. J Biochem Molecular Toxicology, 22(5); 345-353.

[40]. Safarinejad, M. R., Safarinejad, S. and Shafiei, N. (2012). Effects of the reduced form of coenzyme Q10 (ubiquinol) on semen parameters in men with idiopathic infertility: a double-blind, placebo controlled, randomized study," Journal of Urology, vol. 188, no. 2, pp. 526-531.

[41]. Samsulrizal, N. Awang, Z. MohdNajib, M. L. H. Idzham, M. and Zarin, A. (2011). Effect of Ficus deltoidea leaves extracts on sperm quality, LDH-C 4 activity and testosterone level in alloxan-induced male diabetic rats," inProceedings of the IEEE Colloquium on Humanities, Science and Engineering (CHUSER '11), pp. 888-891, Penang, Malaysia, December 2011.

[42]. Saxena, B. B. Demura, H. Gandy, M. and Peterson, R. E. (1968). Determination of steroidal hormones by immunosorbant technique. J. Clin. Endocrinol. Metab., 28: 591-608.

[43]. Seed, J. Chapin, R. E. Clegg, E. D. Dostal, L. A. Foote, R. H. and Hurtt, M. E. (1996). Methods for assessing sperm motility, morphology, and counts in the rat, rabbit, and dog: a consensus report. ILSI Risk Science Institute Expert Working Group on Sperm Evaluation. Reprod Toxicol; 10(3):237-44.

[44]. Sharpe, R. M. (1994). Regulation of spermatogenesis. In: Knobil E, editor; Neill JD, editor. , editors. The Physiology of Reproduction. New York: Raven Press, Ltd; p. 1363-434.

[45]. Shastry, B. (2005). Bipolar disorder: an Update. Neurochemistry, 46(4): 273-279.

[46]. Sule, O. J. Elekwa, I. and Ayalogu, E. O. ( 2012). Effect of Acalypha wilkesiana muell arg. On haematologicalparameters in wistar albino rats. Int J Biol. Med Res., 3(1): 1234-1237.

[47]. Tandon, A. Dhawan, D. K. and Nagpaul, J. P. (1998). Effect of lithium on hepatic lipid peroxidation and antioxidative en-zymes under different dietary protein regiments. J. Appl. Toxicol. 18, 187.

[48]. Tchombé, L. and Louajri, N. A. (2015). Therapeutic Effects of Ficus Carica Leaves: A Brief Review. ARPN Journal of Science and Technology. 5(1): 37-41.

[49]. Teerlink, T. Hennekes, M. Bussemaker, J. and Groeneveld, J. (1993). Simultaneous determination of creatine compounds and adenine nucleotides in myocardial tissue by high-performance liquid chromatography. Analytical biochem., 214 (1):278-83.

[50]. Thakur, S. C. Thakur, S. S, Chaube, S. K. and Singh, S. P. (2003). Subchronic supplementation of lithium carbonate induces reproductive system toxicity in male rat. Reprod Toxicol.; 17(6):683-90.

[51]. Ullah, H. and Khan, M. F. (2014). Mood stabilizing agent lithium carbonate depletes reduced glutathione in human erythrocytes during lithium toxicity. Gomal J Med Sci 12: 237-40.

[52]. Veberic, R. Colaric, M. and Stampar, F. (2008). Phenolic acids and flavonoids of fig fruit (Ficus caricaL.) in the northern Mediter-ranean region,'FoodChemistry,106 (1); 53-157.

[53]. Vijaimohan, K. Mallika J. and Shyamala Devi C. S. (2010). Chemoprotective Effect of Sobatum against Lithium-Induced Oxidative Damage in Rats. J Young Pharm, 2 (1); 68-73.

[54]. Vikas, V. P. Bhangale, S. C. and Patil, V. R. (2010). Evaluation of anti-pyretic potential of Ficus caricaleaves," International Journal of Pharmaceutical Sciences Review and Research, .2 (2), 1-10. 